Binghamton University

The Open Repository @ Binghamton (The ORB)

The Society for Ancient Greek Philosophy Newsletter

3-1991

\title{
Plotinus on the Objects of Thought
}

Eyolfur Emilsson

University of Oslo, e.k.emilsson@ifikk.uio.no

Follow this and additional works at: https://orb.binghamton.edu/sagp

Part of the Ancient History, Greek and Roman through Late Antiquity Commons, Ancient Philosophy Commons, and the History of Philosophy Commons

\section{Recommended Citation}

Emilsson, Eyolfur, "Plotinus on the Objects of Thought" (1991). The Society for Ancient Greek Philosophy Newsletter. 182.

https://orb.binghamton.edu/sagp/182

This Article is brought to you for free and open access by The Open Repository @ Binghamton (The ORB). It has been accepted for inclusion in The Society for Ancient Greek Philosophy Newsletter by an authorized administrator of The Open Repository @ Binghamton (The ORB). For more information, please contact ORB@binghamton.edu. 


\section{Emilsson SF91}

\section{Plotinus on the Objects of Thought}

One of the features by which Neoplatonism diverges from the doctrines of Plato as they are generally understood nowadays is in the Neoplatonic account of intellect and its relation to the ideas. The received view is that according to Plato the ideas, even if knowable by the intellect and in fact the proper objects of thought, exist independently of any mind, whether human or divine, that may contemplate them. The Neoplatonists, on the other hand, all believed that the realm of ideas is to be identified with a realm of a divine intellect, which hence not merely thinks about the ideas, but in some sense is the ideas. Plotinus who appears to be the first to maintain a strong form of this doctrine, claims that the intellect and the ideas are not even two distinct parts or aspects of a thing unified into one (as one might say that the hard disc and the screen of a computer are one); they are one in some much stronger sense so that each idea in all of its parts is intellect and intellect is throughout an idea; thus, intellect without ideas is an impossiblity and likewise ideas without intellect. All this is likely to sound rather peculiar to modern ears. However, I believe that given certain assumptions that Platonists are apt to make, there are philosophically compelling reasons for such a doctrine. It is quite compatible with the spirit of Platonism, if perhaps not with the letter of Plato's dialogues.

In this paper I shall attempt to explain and defend this last claim, focusing on Plotinus. Here is my main hypothesis, which I shall refine and expand in the course of my paper: the strong identity Plotinus maintains between the intellect and its objects, the ideas, can be explained in terms of his acceptance of certain sceptical arguments; in particular he holds that unless the subject and the object of thought are strictly identical, there is room for doubt and error. Moreover, I suppose that Plotinus believed that without this identity the traditional account of the forms as at once ontological and epistemological standards cannot hold. Thus, I am suggesting that we see Plotinus' position here as that of a Platonist who says to his fellow Platonists: if you wish to hold, as you seem to do, that among first principles are included both a universal intellect and the ideas, and that the ideas are to serve as the ultimate standards not only of created things but also 
was to some extent following a tradition, as regards this view he did not hold it just because any sane Platonist would hold it. Moreover, even if he took over the doctrine of the internality of the ideas from his predecessors, Plotinus' version of it is quite distinct and goes beyond anything we can find in those predecessors. This is generally acknowledged. Arthur Hilary Armstrong has suggested in an influential article that Plotinus' particular form of the doctrine arose from a certain reading of Alexander of Aphrodisias' identification of the divine mind in Metaphysics XII 9 with the active intellect of De anima III 5: when the divine mind thinks the ideas it thinks itself. 3 It seems to me that this hypothesis about Peripatetic influence on Plotinus is indeed incontestable.

But if we have a plausible account of why Plotinus came to hold the very strong version of the internality doctrine, why bother about looking elsewhere? What role is there really for skeptical considerations to play? Well, in the most pointed argument Plotinus ever gives for the internality thesis such considerations do clearly play a role. So any full explication of Plotinus' views on this subject has to take that into account. This has in fact been clearly shown by Richard Wallis, to whose pioneering discussion I am much indebted. ${ }^{4}$ What $I$ hope to achieve in this paper is to address the issues from a more philosophical point of view. My understanding of Plotinus' text also differs from Wallis's in some significant ways. But let me state right now that there is no conflict between my hypothesis and accepting the influence of Aristotelian noetics. My hypothesis is primarily concerned with Plotinus' philosophical motivation for holding the strong internality thesis, the claim of noetic influence has more to do with his conception of it.

\section{Ennead V. 5.(32) $1-2$ and V. 3.(49) $1-5$}

In the first two chapters of Ennead V. 5. (32) to which Porphyry gave the title "That the intelligibles are not outside the intellect and on the good"s, Plotinus argues that the intelligibles are internal to the universal intellect.

3See Alexander of Aphrodisias, De anima, p. 89, 22-3 and Mantissa 112, 18-13, 2 (Bruns). 4"Skepticism and Neoplatonism" in W. Haase (ed.), ANRW II. 36. 2, p. 911-54.

5This treatise is part of the "Grossschrift" consisting of III. 8, V, V. 5 and II 9, which were made individual treatises by.Porphyry. V. 5 is in content especially close to V. 5, which precedes it. 
and I have shown elsewhere why it is not tenable. ${ }^{6}$ It is more likely that his opponents are either Aristotelians or Stoics, or Platonists influenced by either one of these schools. They are people who believe that the intellect has demonstrative knowledge while admitting that the first principles of the demonstrations are immediately known. It seems to me that Aristotelians or Aristotelizing Platonists are the most likely candidates.?

But what is the structure of Plotinus' argument here? In particular how is what he says about self-evidence in the intellect related to what he goes on to say about perception? And what precisely are Plotinus' points about perception? As to the former question, I think the point is that the trustworthiness of those intellectual truths that are admitted to be self-evident cannot be founded on sense-perception, a doctrine Plotinus may take to be advocated by Aristotle in the Posterior Analytics 19. This is so firstly because even in the case of the clearest sense-experiences, when unaided by reason and intellect, we can ask whether their objects exist only in our affections. Secondly, even granting that what is to be grasped in senseperception is in external sensible objects, nevertheless, what is known through sense-perception is only an image of the thing, which itself remains external. Some light is thrown on what Plotinus means by this last point at the beginning of chapter 2 , where he summarizes the main points of chapter 1. It becomes clear there that what he means by "image" (eidolon), which sense-perception is supposed to grasp, is the quality of each thing as opposed to its essence or quiddity. Thus, contrary to what one might suppose from these lines in chapter 1 taken in isolation, Plotinus is not saying that the senses grasp only what they have taken on as opposed to what exists in the object independently of being perceived. I shall retum to this point in a little while. But supposing that what I just said is right, we can fit the point with what I said before about criticism of Aristotelian views: if perception knows only how things are qualified, but not their essences, intellect cannot obtain its clearness concerning what it immediately knows from sense-perception. For what the intellect knows immediately, also on the Aristotelian theory, is

6See E. K. Emilsson, Plotinus on Sense-Perception: A Philosophical Study (Cambridge, 1988), pp.

${ }^{7}$ Cf. Anal. pr. 64b35; Anal. post. 76b23; Top. 100b1; Phys. $193 \mathrm{a} 5$. 
its images, not of the object as it is in itself for it can have no direct contact with it.

In chapter 1 Plotinus also says that if the objects of intellect are external to it, the intellect would not recognize justice and beauty, for instance, for the principles of judgement for justice and beauty would be outside the intellect (lines 29-33). I take it that in his view the principles of judgement for justice and beauty are the ideas of justice and beauty themselves. A little later (lines 47-51) he says that if the objects of intellection are outside the intellect, the intellect would at most grasp something analogous to images in gold made by some sculptor or engraver, and intellect's awareness of would be like sense-perception: a grasp of mere images while the real thing (corresponding to the idea in the craftsman's mind), would escape it. And if the intellect grasped such images of the real thing, he asks, why should one thing that the intellect grasps be justice and another beauty?

Why should the intellect have a difficulty recognizing justice and beauty if it grasped images of them? The point of these passages-a point Plotinus himself explicitly makes-is that unless the ideas are really internal to the intellect they (and thereby everything else) will be unknowable. The ultimate standards of truth for a Platonist is of course the ideas; if they themselves are outside the divine mind and the divine mind has only images of them, its knowledge will be second hand; the image of justice that the divine mind had access to, would be something that may have the quality of being just, but it would not be justice itself, but a mere typos of it. And in order to know the image for what it is, i. e. the image of justice, the divine mind would have to refer to the idea itself; the image would be only the idea expressed in and through something other than itself. Hence, the intellect would need a ground or justification, which it cannot in principle have, for declaring the image of justice to be that image rather something else.

In chapter 2 Plotinus makes it very clear that the mind with all its contents is evident to itself and that the real truth, which it contains, i.e. the ideas, "does not agree with something else, but with itself, and there is nothing in addition to it, but what it says that is what it is, and what it is is what it says" (lines 18-20).10 I take the point of this to be the following:

101 do not see that it is necessary to alter the text here as Theiler does, followed by Armstrong. My translation is based on the H-S text. 
than the expressions or the expression parts in which they are referred to. The idea is again that the ideas in the divine universal mind are not expressions that express (mean, correspond to or signify) something other than themselves. For on the level of thought expressions are just like mere representations on the level of being.

How, then, does Plotinus think that the intelligibles are internal? What is the mode of thinking in terms of the things themselves rather than any representations of them? This is a large and complex issue that I cannot address in its entirety here. But I shall make a few comments concerning Plotinus' clearest presentation of it, the one he gives in V. 3 .

In this treatise Plotinus discusses the question of self-knowledge. He asks which faculties, if any, have self-knowledge. Sense-perception is ruled out on the ground that it only knows what is external to itself. Discursive reason, which in Plotinus' view is the faculty with which we identify our empirical self, is rejected as well for basically the same reason: it is concerned with representations that come to it from something else, i.e. from sense-perception below, as he puts it, and from intellect above (chapter 3).12 However, he does seem to hold that discursive reason has selfknowledge of a sort: it knows, for instance, that it is discursive reason, that it gains understanding of the things outside it, and that it judges what it judges. But this is not genuine self-knowledge, because discursive reason knows these things discursively, i.e. by means of representations derived from the pure intellect (chapter 4, 15-28). Thus, discursive reason is not directly reflexive.

Intellect however is. In the next chapter Plotinus develops what is perhaps the subtlest and philosophically most interesting of his many accounts of the nature of intellect. The first point to be established is that for intellect to have a more perfect kind of self-knowledge than discursive reason it cannot be, as it were, two things unified into one thing so that it knows itself in the sense that one part, the thinker-side, knows the other, the object side of thought. In that case intellect as a whole would not know itself completely, for the thinker-side would not know itself at all. Thus, we have have a claim to the effect that even a subject-object distinction in the

12V. 3. 3-4; cf. IV. 3. 30 and I. 4. 9-10. 
Perhaps [intellect] will add the one who has contemplated from itself, in order that it may have thought itself completely; but if the one who has contemplated, then at the same time also that which has been seen. If now that the contemplated belongs to the contemplation, if [these contemplated objects] are impressions of them, it does not have them themselves; on the other hand, if it has them themselves, it does not have by seeing them as a result of dividing itself, but it both saw them and had them prior to the division. If this is so, the contemplation must be the same as the contemplated and the intellect the same as the intelligible. (V. 3. 5, 17-23)

Unfortunately I am not confident that I follow the argument here step by step, but it seems to me that considerations such as the following are at least a part of what he saying: Suppose intellect is divided into a thinker side (or subject) and object side. Suppose also that the subject includes itself as its own object. Suppose in addition that intellect knows the original intelligibles themselves rather than impressions or representaions of them. Then, in the same act as it apprehends itself, it will also apprehend the objects of the thought of the subject. Now, these objects as apprehended in that act whereby the intellect apprehends itself are either impressions or originals. If the subject as such does not contain the originals it could only see impressions by directing itself toward itself, for there were no originals there. But this cannot be so, for it is assumed (though not argued for yet here) that intellect knows the originals. Hence, it cannot know them by dividing itself into a subject side that does not contain them and an object side which does. Hence, the subject must have seen and contained the originals from the beginning. This is really a reductio argument against the hypothesis that the intellect is divided into a subject side and an object side on the assumption that intellect does in fact possess the real things themselves. Then, Plotinus moves on to restate a point familiar from V. 5: intellect must know the real things themselves, for else there can be no truth: "for truth ought not to be of something else, but what it says, that it should also be." To summarize: if intellect is to know the things themselves and itself, the subject-object distinction must be abolished; but intellect does know the things themselves; hence, intellect is not divided into a subject side and an object side. 
and the inner act of $F$, which we mentioned before, all turn out to be the very same thing: pure F-thoughts.

\section{The conclusions so far seen from a wider perspective}

In Plato's dialogues the ideas are supposed to be causes of sensible things, which have the character they do in virtue of participating in the ideas or imitating them. The ideas are perfectly that which they cause in other things; or otherwise stated they are necessarily and essentially that which other things are only contingently and superficially. Thus, we may say that the ideas are perfect standards of what else there is. But the ideas are not only standards of what is, they are also standards of knowledge. They are according to Plato the only objects of knowledge and, moreover, they are supposed to be such that once we have made acquaintance with them, there is no room for error or doubt with respect to them: they somehow bear their true identity on their surface so that in their case appearence and reality collapse into one another. Plato clearly thought that any kind of skepticism with respect to the knowledge of the ideas is precluded: in their case there is no veil of appearence between them and the knowing subject. By postulating entities such as the ideas in which the standards of being and the standards of knowledge coincide, Plato thought that he could avoid the perils of relativism and scepticism widespread in his own times. That is exactly what Cherniss has called "the philosophical economy of the theory of forms".17

I suggest that we see Plotinus as being in perfect agreement with the Platonic program. Moreover, he shares with Plato all the essential views about the nature of the ideas: they are necessarily what they are; and they are standards and causes of whatever else there may be; furthermore, they are standards of knowledge: we refer to the forms or rely on our knowledge of them when passing judgements on sensible things ${ }^{18}$ and they themselves are self-authenticating to the mind thinking them. Plotinus only insists that if

\footnotetext{
${ }^{17}$ H. Cherniss, "The Philosophical Economy of the Theory of Ideas", American Journal of Philology LVII (1936), 445-56).

${ }^{18}$ For a detailed recent discussion of this see $\mathrm{H}$. Blumenthal, "Plotinus and Proclus on the Criterion of Truth" in P. Huby and G Neal (eds.), The Criterion of Truth (Liverpool, 1989), pp. 257-80.
} 
that is what it is, and what it is is what it says". In this doctrine we see the notion that the standard or criterion of $F$ must at once be that very thing of which it is the standard or criterion, namely $F$, and in being $F$ it must somehow "say" that it is $F$. The intellect's thought about $F$ is not true because it corresponds to $F$ itself; it is $F$ itself and being $F$ itself and at the same time a thought it is the knowledge and announcement of $F$. This does at first sight appear very mysterious. However, Plotinus idea behind this claim is readily understandable. Perhaps the best way to expound it is through analogous cases from later philosophy.

Wilfred Sellars launched an attack on what he called "The Myth of the Given".21 In particular he has traced in the tradition of empiricism a notion, mostly implicit rather than explicit, of items which are at once supposed to be items of a certain kind and instances of knowledge of that kind. That is to say in the empirical tradition a given sensation (sense datum, impression, sensum, phenomenal quality) is supposed to be both something green and an instance of awareness or knowledge of something green. Such items may seem to provide a solid foundation of knowledge and meaning, for they bridge the gap between what is and what is within the reach of our minds: the very same thing is an F and is our direct awareness of F. Now, Sellars's attack on the Myth of the Given, consists in undermining the coherence of this very notion or at least of the claim that sensations are plausible candidates for something which at once is and is knowledge of itself such as it is. However, he seems to agree that if there is a given it must be such as he describes it, namely a thing which is both of a certain kind and knowledge of something of that kind. In other words, if there is a given, it must be just as Plotinus says the intelligibles must be: it is "knowledge of itself such as it is" or "that which it is is what it says". I believe that Sellars is quite right in his analysis of empiricism and I believe that he is also right in his contentions about what the given must be like, if there is such a thing. Moreover, it is fairly clear that what Plotinus is after in his account of the identity of the intelligibles and the intellect is a notion of a given. Furthermore, it must be said in his praise that he shows a deep understanding of what it takes for there to be a given, and as opposed the empiricists' view, his account of it

21 See especially Science, Perception and Reality (London and New York, 1963), pp. 69-70, 129-34 and 156-61. 
have to be such that from it one could read off all the correct applications of the expression expressing a given meaning. It seems to me that any feature that is to accomplish this must have the characteristics of Plotinus attributes to the intelligibles.

In surveying candidates for determinants of meaning Kripke briefly mentions Platonism in connection with Frege's views. Frege's Platonism is of course the sort of Platonism according to which mathematical objects exist as Platonic "ideas" independently of any mind. Expressions have a certain "sense" associated with them that is likewise an objective non-mental thing. This sense determines the reference of a sign, which in the case of mathematics is a "Platonic" objective mathematical entitiy, e.g. a the plus function. But for people to grasp the sense associated with a sign, they must have appropriate ideas in their minds associated with the sign. According to Kripke it is in relation to the alleged function of these mental ideas that Wittgensteins skeptical problem about meaning sneaks in for a Platonist of the Fregean sort:

[The skeptical problem] arises precisely in the question how the existence in my mind of any mental entity or idea can constitute "grasping" any particular sense rather than another. . . . For Wittgenstein, Platonism is largely an unhelpful evasion of the problem of how our finite minds can give rules that are supposed to apply to an infinity of cases. Platonic objects may be self-interpreting, or rather, they may need no interpretation; but ultimately there must be some mental entity involved that rasises the sceptical problem. ${ }^{23}$

Suppose one is willing to go along with Platonism in holding that Platonic objects in themselves are self-explanatory (or need not interpretation), while insisting that what anybody, including God, can have access to is at best certain mental representations of them, which however fail to give us the real things themselves. The obvious move would be to maintain that the ideas are in fact internal to the mind. This is of course just what Plotinus does. Objectivity and unversality are preserved because the mind in question is a universal and divine one.

${ }^{23}$ S. A. Kripke, Wittgenstein on Rules and Private Language (Cambridge, Mass.1982), p. 54. 
representations and hence not the sort of thinking the universal intellect is constantly and eternally engaged in, nevertheless we can momentarily rise to that sort of thinking ourselves, which for Plotinus means that we can become the universal intellect. In this context it is worth pointing out in addition that Plotinus is not so much concerned with answering skeptical arguments directly. I suspect that rather he the kind of philosopher who believes that skepticism leads to absurd consequences. Nevertheless, he would grant that skepticism shows that no commonsensical account of the foundation of knowledge will do. So his message to other dogmatic philosophers is that unless they are willing to go along with him and posit a universal intellect with the features he claims for it, there is can be no secure foundation for knowledge.

It may be natural for us to see what Plotinus is doing as a correction of Plato: he may sound like someone saying that Plato was essentially right but he failed to see that the ideas must be internal to the divine mind and that the doctrine must be set straight in this regard. However, this is almost certainly not how Plotinus saw the matter himself. He certainly must have thought that what he is claiming was also Plato's view and that this could be seen if one studied him carefully and intelligently. I shall not attempt to detect the train of argument in Plotinus' Plato exegesis, still less undertake a defense of it. However, two remarks are in order. First of all the main source for a divine mind in Plato is of course the demiurge in the Timaeus; moreover, the demiurge is said to gaze at the ideas, which may suggest that they are something external to him. However, it is clear that on any account the story of the deniurge cannot be interpreted as the literal truth, for instance, being a mind, $h$ does not really gaze as if with eyes. Hence, Plotinus would say the matte is not at all settled against internal forms on the basis of the Timaeus. Secondly, it may be claimed that Plato explicitly denies that the ideas are mental items of any sort in Parmenides 132 B-D. However, there may be ways to avoid attributing this conclusion to Plato himself. For instance, Plotinus may have thought as Proclus surely did that the first part of the Parmenides raises a number of difficulties conceming the theory of ideas, all of which are to be solved. He may have thought, in my view quite plausibly, that the apparent refutations there do not present Plato's final judgement. 